\title{
ANIMAL TURN AS A META-TURN? ${ }^{1}$
}

\author{
HANNA MAMZER ${ }^{1}$ \\ ${ }^{1}$ Adam Mickiewicz University in Poznań, Szamarzewskiego 89 C, 60-568 Poznań, Poland. ORCID: 0000- \\ 0002-2251-7639,E-mail: mamzer@amu.edu.pl
}

ABSTRACT: Human sciences as a reflection of social transformations fluctuate with dynamic changes of current cognitive paradigms. Following the textual and visual turn and the turn towards things (objects), there are intensified tendencies to think in terms of an "animal turn", which becomes close not only to activists and pro-animal activists but also to scientifically engaged humanists. I believe, however, that the animal turn should be treated as a meta-turn: a process that requires a change in the relationship between the reflecting subject and the object of reflection, and not only as a specific kind of representation of the surrounding world. In the proposed text, I attempt to analyze the causes of the turn towards animals. I also address the theme of cognitive resistance in view of the recognition of animal studies as a fully-fledged theoretical and research area of contemporary humanities.

KEYWORDS: animal turn, turn to animals' relations, man, animal, animal studies

Nowadays, humanities and social sciences when attempting to describe and analyze the social and cultural reality are guided by cognitive pluralism, embedded in a postmodern perspective which proposes to adopt the assumptions of the process of inter-

\footnotetext{
${ }^{1}$ This article was published in Polish as subchapter titled "Zwrot animalistyczny jako meta-zwrot" in Mamzer Hanna and Isański Jakub. 2018. Socjologia kultury w świecie inteligentnych zwierząt $i$ uczących się maszyn. Bydgoszcz: Epigram.
} 
preting reality for all the reflections. We must however be ready to accept the consequences of these assumptions: the obvious existence of many interpretations of the world. Each of these interpretations is realized through a unique kind of discourse based on a peculiar metaphor and a peculiar language. The multitude of the created mental worlds makes us realize that the reflecting subject has no access to the world as such - it has access only to the representation of the world, created through the mind that discovers this world. As I wrote in another place: "The concept of representing reality through various forms of reflection arises in humanistic discourse from the approach proposing the assumption as the basic thesis that objective recreation of reality is not possible, that it always requires the use of a kind of "community" perspectives (borrowed, of course, from the influence of culture and social context) that alter not only the form but also the meaning of the analyzed phenomena. Psychologically, this is a universally accepted process when considering the accuracy of human perception. However, the popularization of approaches emphasizing the importance of interpretation has also allowed to propagate the idea of transforming the perceived world, not only on the level of mental processes taking place in the mind of the subject, but above all on the level of socially regulated cultural processes that influence the way of seeing, writing and understanding the world and the way of transferring the knowledge about it" (Mamzer 2008: 62).

The representation of the reality through the metaphors of discourses has until now taken two significantly visible forms - textual turn embedded in poststructuralism and carrying a rational message, and the opposite visual turn embedded in postmodernism, which restores intuition and emotions and their role in human perception of the world. This opposition was formed on the basis of the Cartesian concept of psycho-physical dualism: not only antagonizing these two ways of cognition, but also hierarchizing them in such a way that the discredited emotional cognition was for many years removed from research practice as inferior, unworthy and... feminine. The Descartes' way of looking at the world of living beings only strengthened the vision already proposed in ancient times, especially by Aristotle: "The post-humanistic perspective is associated with animal studies only when it implies a critical attitude towards anthropocentrism and not an anticipation of the post-human or the post-human era. In our culture, the privileged status of man inherited from the Greeks and strengthened by Christianity involves the glorification of the mind, the language and the immortal soul" (Bakke 2011:199). Thus, both the hierarchical perception of the world built on anthropocentrism and the strengthening of psychic-somatic opposition (and thus: emotional opposition and rational perception of the world) were sanctioned.

Over the last forty years, however, there has been an intensification of yet another tendency, which I initially thought of contrasting with textual and visual turns, although after a thorough reflection, I think it is a meta-turn. If this concept is introduced, then in terms of a meta-turn we should define such changes in the pattern man relates to the world that not only refer to the way of representing the world ("visual" or "textual"), but also refer to the model of perceiving its construction. In this sense, a potential animal turn would have to be approached at a similar level of generality 
as a turn "towards things". Such a structure of at least two levels of thinking about the world seems conceivable, particularly as the empirical observation inclines to this reflection. More specifically, the social awareness of the relationship between man and the rest of the living world takes on a polarized form today: on the one hand, through functioning in post-industrial societies, we lose contact with nature in its broadest sense, animals become only theoretical constructs, whose presence is justified with names, and contact with them is basically limited to the consumption in various forms and shapes (de Mello 2012). There is also an increasingly dynamic reflection on whether an anthropocentrically oriented world is the only world and on the consequences of the current human approach to nature for future generations. After many earlier cognitive turns, limited basically to the metaphor of logos, the turn towards animals, deepens the post-humanistic reflection on the responsibility of the human being for the rest of the living world and for relations with this world, also in a pragmatic dimension.

The two aforementioned approaches to perceiving the reality reflect certain methods in the application of different discourses - involving distinct methods of viewing and describing the world. It should be recognized, however, that these are "methods of representing the world" precisely through the use of specific metaphors. These turns, however, have a different character than two subsequent meta- turns: a turn to things and a turn to animals. They should gain the meta status, which means changes not only in the method of perceiving the world, but above all in the method of creating relations with the surrounding and researched world. K. Weil has a similar opinion:

If the linguistic turn insisted that we have no access to unmediated experience or knowledge but only to representations that are themselves fraught with linguistic and ideological baggage, the turn to animals can be seen as responding to a desire for a way out of this "prison-house of language". It responds to a desire to know that there are beings or objects with ways of knowing and being that resist our flawed systems of language and who may know us and themselves in ways we can never discern (2010:9).

The turn towards things (which I will not address in this text) was most strongly observed in history (including archaeology) and sociology. As Ewa Domańska writes: "The interest in things and animals and the successive turns (a turn towards things, materiality turn, as well as a performative turn or agency are not the result of intellectual fashions, cognitive curiosity of avant-garde researchers, but are the result of a growing conviction that current ways of perceiving the world do not reflect the changes it undergoes (genetic engineering, transplantology, psychopharmacology, nanotechnology)" (2008:12). While on an archaeological level the turn towards things brought interesting conclusions and proposals (and on a historical level it could bring) (Domanska 2008), on a sociological level it turned out to be a dead end leading to a kind of cognitive impasse: by offering the attractive on a performative level practice of visual representation of things, on a reflective level it turned out to be completely futile. This is because the cataloguing of images of reality does not show anything, as long as it is devoid of verbal commentary. W. J. Thomas Mitchell has already noticed this in Picture Theory Essays on Verbal and Visual Representation (1994) while discussing the impact of a photo-essay. Sociologically, the turn towards things was supposed 
to attribute to things the driving force of provoking and modifying social relations, as well as the secondary function of the effect/product of those relations.

In this paper, however, I would like to focus on the increasing interest in a turn towards animals - a post-humanistic way of revaluating relations between man and the surrounding natural world, especially the animal world. On the discourse level, it is visible not only in humanities, but also in social sciences and sciences as well2. Such discourses serve to describe the observed social and cultural reality that questions the hitherto anthropocentric being in the world, for the sake of sustainable development, ecoservices and partnership relations with the natural environment. The change in these relations is reflected in the activities at various levels of generality: from global political decisions ${ }^{3}$, to local solutions at meso-level ${ }^{4}$ to local practices of small communities. ${ }^{5}$ and ending with individual choices and consumption trends (e.g. eco-parenthood, vegetarianism, veganism, etc.). In this sense, the particularity of the animal turn lies not only in the change of discourse, logos and the subject itself, but also in the change of the level of empathy. The person who writes about animals and has no relationship with them is detached from the subject matter. This creates a sense of being non-substantive, which is basically paradoxical, because it seems that the cognitive-relational transformation we are talking about here - especially on the Polish ground - was initiated by literary scholars and linguists (feminized disciplines - or, therefore, more emphatically approaching the environment?). The necessity of establishing the link between humanities and natural sciences is also noticed by Ewa Domańska who writes: "When looking at the historical research from the point of view of cf. rative research on the theory of humanities, the possibility of refreshing reflections on the past I see: first of all, in the development of the re-established dialogue between humanities and natural sciences" (2008: 27). The mutual resentment of historians and natural scientists, described by Domańska, is not only typical for history. Unfortunately, other areas of humanities also present a similar attitude. Undoubtedly, establishing a transdisciplinary dialogue is not easy - nevertheless, especially in the context of animal studies, it is necessary. Because the turn in the relationship between humans and other animals is defined as such, the need to determine in whose interest do we conduct our research at all seems cognitively basic. The production of knowledge on animal studies disturbs the existing structure of knowledge, forcing confrontation with the unknown: at the level of humanistic discourse it becomes too abstract and must be confronted with the realities of animals. This question is answered by Pedersen (2014), who was quoted earlier, with the title of her text: „Knowledge production in the "animal turn": multiplying the image of thought, empathy, and justice” - suggesting that the production of knowledge in the field of so-called animal studies should lead to building empathy, reflection and animal rights. The author continues to write: "In the animal turn we are indeed doing theory, but we are not doing theory in

\footnotetext{
${ }^{2}$ Where, for example, on the grounds of pragmatic zootechnics, animal welfare is widely discussed. cf. Kołacz, Dobrzański 2006; Gardocka et al. 2014.

${ }^{3}$ The rejection of the CETA agreement by Belgium (BBC News 2016).

${ }^{4}$ Firecrackers and fireworks banned in Rome (TVN 24 2016).

${ }^{5}$ The residents' resistance to investments that affect the environment.
} 
complete isolation from the actual life situation of animals; we also want to develop a knowledge base for theoretically informed action and politics for animals that intervenes in processes of escalating oppression. one of the driving forces behind the formation of the animal turn research theme at Lund University was the question of how we can create a space in academia where an animal perspective is present: A space which allows us to speak about, and also work to change, the experiences of animals in human society" (2014: 17), which leaves no doubt about the need to combine theoretical considerations with animal welfare practice.

Are the humanists ready for this? Pedersen says: "As a social scientist, I acknowledge my ignorance and my own disciplinary limitations in the area of animal sentience and behaviour, and greatly appreciate the expert knowledge that ethologists and other scientists bring to these dimensions of the "animal turn". (2014:14)- and this testimony should be treated as an illustration of the commonly occurring situation, which also occurs in Poland. Many representatives of humanities involved in the activities within the framework of the animal turn openly declare that they are not able to be confronted with tangible empiricism that presents the actual actions of people towards other animals. This is not only a significant cognitive challenge, but especially an emotional one: empathy and even syntony. Monika Bakke already in 2011 presented it as follows: "Since the 1970s, we have been witnessing the formation of new academic disciplines that are committed and from the very beginning inherent in various forms of activism. These include studies on gender, trauma, homosexuality, women, and animal studies. The latter would lose their vital strength and sense of existence without contact with specific practice and direct or indirect involvement in animal rights activities" (2011: 200) and further on: "Probably the most serious of these allegations is the lack of connection between theory and practice, which means a real animal being. It is not so much a question of finding a compromise research path that would neutralize controversy and avoid politics, but rather of taking care of the relationship between discipline and social practice” (2011:200), and human practices towards other animals. The postulate indicated by the author is therefore extremely important: it is impossible to undertake actions or reflections in the field of animal studies, without contact with the knowledge about animals and without contact with the knowledge about how they are treated by humans". Steve Best, one of the founders of the Institute for Critical Animal Studies, clearly emphasizes the necessity of the connection between theory and practice, demanding more radical attitudes from academics; while Susan MacHugh warns that turning only in the circle of metaphors exposes us to "the danger of reaching the same old conclusions that animals are just lite subjects for humans" (Bakke 2011: 200). As Bakke writes: "If we assume that the current increased interest in human-animal relationships is a sign of a kind of animal turn, then in order to understand its meaning, we must first consider its causes and context. On the one hand, these are social movements, the development of science and technology, and on the other - within the framework of the academic debate - the need to rethink the position of a human - subject in the face of anti-essentialist trends in humanities. Let us remind ourselves that a favourable context for the development of animal studies appeared already in the last century thanks to the movements for 
civil rights, women's rights and ecological rights, especially those of a non-anthropocentric character, such as the movement for the liberation of animals and deep ecology" (Bakke 2011:194).

According to Wolfe (2011:1), animal studies did not function as a separate field of humanistic reflection until 1995: "there was no animal studies when I published my first essay in that emerging field in 1995". Wolfe claims that the terms "man" and "animal" are now relicts of humanism (2011:3), flattening the complexity of the definition of who is one and who is another.

The phrase "animal turn" as a phraseological term was probably used for the first time in 2003 by Sarah Franklin during a conference organized by the Cultural Studies Association of Australasia", writes Pedersen in her text with a significant title: Knowledge production in the "animal turn": multiplying the image of thought, empathy, and justice. The author states: "in their book Knowing Animals (2007), Philip Armstrong and Laurence Simmons trace the phrase "animal turn” back to 2003, when Sarah Franklin brought it up during the Cultural Studies Association of Australasia conference. In 2007, Harriet Ritvo notes in the journal Daedalus that the "animal turn" suggests new relationships between scholars and their subjects” (Pedersen 2014:13). Referring to the above-mentioned authors, Pręgowski also raises the issue of the increasing expressiveness of the animal turn in the humanities. Particularly important for this text is Ritvo's statement suggesting a change in the relationship between the cognitive subject and the object of cognition, which in the case of the animal turn is of particular significance. The essential sources of the animal turn should be sought in attempts to redefine the relationship between man and nature and in reflecting on the essence of subjectivity. The redefinition of the binary opposition of humanistic nature-culture proposed by Braidotti (2013) and the consideration of human culture as a natural extension of nature, the adaptation of man to the requirements of the environment through the creation of such an intersubjectively communicable set of normative and guiding rules, abolishes the dilemma of philosophy concerning the reflection on how much is there of an animal in a human being. The continuation of these reflections redefines the subjectivity which, according to Braidotti, is anyone who can build relationships: therefore, people and other animals. The change in the perception of the relationship between man and animal brings perhaps the most spectacular questions in the form of Bruno Latour's reflections on whether, as a species, we have even gone beyond nature? It is strengthened by the opinion of Donna Haraway, who says that "we have never been human", because today it is obvious that as people, at the same time, we are always non-humans by necessity. We - i.e. the living bodies - participate in the exchange of matter and energy with the non-human environment. Also, at molecular level we are not only human: we discover in ourselves animals, plants and microbes. It is the critical posthumanism that underlines our material condition, not to regret it, but, on the contrary, to add value to it. (Bakke 2011: 199). In Poland, the problem of reformulating animal-human relations is also included in the area of important reflective considerations (but also within specific activist initiatives). While in the social practice of everyday life this is becoming more and more visible, insofar human-animal studies, also called animals studies, have a difficult access to the aca- 
demic world: "In Poland, animal studies, understood as a field of research, have been in existence for some time now, albeit in a rather modest dimension, but they are not yet present as a separate academic discipline" (Bakke 2011: 194). Social demand for education in this area is increasing significantly, however, in the scientific and academic worlds, animal studies are hardly adopted. This issue provokes reflection on the existing state of affairs.

There are three reasons behind this - firstly, the introduction of the animal studies into the curriculum of academic teaching can be interpreted as an indication of the collapse of the modernist system of exercising positivistically oriented science. Regardless of whether it concerns the sciences or broadly understood humanities. Animal studies naturally introduce empathy and feeling in irrational terms and from the position of animals other than humans. This questions the standard "hard research methods" as the only applicable means of cognitive, legitimate research activity. The introduction of this kind of reflection is a precedent for the appreciation of the emotional perception of the world and the cognition through intuition. The area of animal studies is dominated by women's cognitive activities (as well as the activist area of activities for animals) ${ }^{6}$. The admission of such a cognitive trend and such authors appreciates their creative activities. Thirdly, the reflection on the attitude of humans and other animals towards each other leads to questioning, or at least testing, the stability of anthropocentric behaviours. These three reasons have a common denominator: it is the destabilization of the existing order embedded in established hierarchies and allowing to function without going beyond the sphere of comfort. All three features described above cause that this frozen, safe situation is redefined in a dynamic process, in which it is necessary to learn to act effectively again, and what is more, taking into account the changed axiological assumptions. Ritvo claims that there is still much to be desired on the issue of full recognition of animal studies as a valuable scientific discipline: "Within my own experience as a scholar, the study of animals has become more respectable and more popular in many disciplines of the humanities and social sciences, but it is far from the recognized core of any of them. It remains marginal in most disciplines, and (not the same thing) it is often on the borderline between disciplines" (Ritvo 2007: 121-122). Similar opinions are expressed by Monika Bakke (2011): "Expectations towards researchers are high, as they are required to reject the known and accepted methodology - imposing the necessity of reformulating opinions, entering the unknown, not to mention such obvious aspects as the necessity to observe the world literature and actively participate in current debates. Unfortunately, however, this invigorating attitude is met with open criticism at our universities, and often with hostility because there are still accusations of novelties and faddism and, above all, it is considered unbearable to engage politically or emotionally in the subject matter of research, which allegedly completely discredits its scientific character. But it's not all about the blind engagement, it's more about the critical empathy" (2011: 203). It should be emphasized that "Recently in Poland there has been a growing interest in

${ }^{6}$ Cf. Empathic Misanthrops? - image of people working in non-governmental organizations for animals. Research Report. 2012. 
the subject of human-animal relations, which is reflected in the rapidly growing number of publications, exhibitions, debates and conferences on these issues. This trend has emerged much earlier in the West and has already resulted in a new transdisciplinary research area and institutionalized academic discipline, namely human-animal studies or animal studies" (Bakke 2011: 193)7. The author also believes that "Animal studies in Poland still focus primarily on humans and are still far on the margins of academic life, having an incidental and fragmentary character" (2011: 201). Unfortunately, despite the passing years, this description still accurately reflects the state of animal studies at Polish universities.

It would be hard not to agree with Bakke, who says that "In Poland, the animal turn is taking place slowly but noticeably - for example, during the recent presidential elections, when many of us realised that, like others, we do not support the killing of wild animals for entertainment and expressed it publicly. There are probably many factors of moral evolution that have led us to the point where formulating such an accusation is not synonymous with being ridiculed. What matters is the change in sensitivity and its specific effects - the saved animal lives - and the social pressure forced the hunter to put down his weapon and refrain from the pleasure of hunting" (2011: 198). Indeed, the animal turn is gaining momentum ${ }^{8}$. The demand for education in this area is therefore growing.

A change in the perception of the relationship between a human being and an animal is a multi-layered phenomenon that takes place at the level of individual and social consciousness, expressed with the help of various logos and practices. There are also changes in the axio-normative systems regulating human activities - the appearance of a debate on the moral status of animals - promotes equality and justice in relation to animals, treating speciesism on equal basis with intra-human discrimination (racism, sexism, ageism, etc.). This erodes the carefully cultivated border between humans and other animals and shifts the hitherto unambiguous demarcation line between humans and other animals, created with the help of science and humanities in all fields of academia, culture and history. The fact that this border is fluid and the division itself is a social construction facilitates its relativization and weakens its power (although abolishing some borders requires establishing others). Paradoxically, however, talking about the border strengthens it - as Ritvo claims: "the regard to the study of animals, this often means that explicit claims of unity (humans are animals) paradoxically work to rein force the human-animal boundary they are intended to dissolve. That is to say, such claims incorporate a grudging acknowledgment that this boundary is widely recognized and powerfully influential. Why else would it be continually necessary to deny its validity or remind ourselves of its arbitrariness?" (2007: 119).

Reflection on the existing anthropocentric orientation of human activities has led

\footnotetext{
${ }^{7}$ Ritvo shares this opinion: „,nevertheless, during the last several decades, animals have emerged as a more frequent focus of scholarship in the humanities and social sciences, as quantified in published books and articles, conference presentations, new societies, and new journals" (2007: 119).

${ }^{8}$ In this context, we should give the unprecedented examples of the blocking of hunting in Wielkopolska, which was carried out by animal activists in 2015 , as a continuation of the example cited by Bakke.
} 
to an increased awareness of the negative effects of this dichotomous attitude of humans towards other animals (on the one hand, loss of contact with them, and on the other hand, intensification of consumption of zoonotic and animal-based products); raising awareness of animal welfare neglect, in particular in the light of increasing knowledge of animal ethology and animal needs, the impoverishment of eco-system homeostasis through carbon dioxide emissions (particularly those resulting from mass production of animals), improper waste management, tropical forest deforestation for crops essential for the feeding of farmed animals (in particular genetically modified soya), overproduction of animal protein (and milk and meat), climate change imbalances and the introduction of genetically modified organisms into the environment.)

The civilizational development, enrichment of societies and the increase of living standards and the quality of life result in higher empathy and care for the natural environment and its resources, as well as the in the awareness of the necessity to implement the principles of sustainable development (especially in the context of excessive animal production). The progress of civilization is commonly treated as a determinant of the relation to animals. These processes are facilitated by the general access to information related to the effects of anthropocentric attitudes exploiting other animals.

Academic resistance to the recognition of the animal turn as an undeniable fact, expressed in the reluctance to accept animal studies as a full-fledged research field of a complex heterogeneous character, bears the marks of a Freudian mechanism of ego defense: either denial or negation. Not without reason, I mention the notion of "ego", which should be treated as an analogy of the institutional status quo.

Introducing animal studies into the academy and simultaneously addressing the challenges posed by the animal turn, questions the established and respected principles. Fear of disturbing those principles requires the rejection of these areas of interest as unserious, emotional and irrational. I have an impression that the postulate of combining theory and practice of empiricism, abstract considerations with concrete findings, arouses particular discomfort. One can get the impression that it is precisely this jumping from the world of abstraction to the world of concreteness that is inconvenient for many.

The recognition of the animal turn as a fact has yet another kind of consequence: it forces us to notice, and blocks the unnoticed, unethical and immoral exploitation of animals, which homo sapiens reproduces every day on a massive scale. Awareness of this scale and these practices is one thing. However, the next challenge is to confront this awareness with own individual choices as to the extent to which I want to participate in the Holocaust of animals. It is not convenient to confront these issues and it causes discomfort - first of all the mental discomfort - it forces us to go beyond a comfortable and safe circle of well-established findings. We are obliged to address ethical issues related to our coexistence with animals. Not because their lives influence ours. But because ours influence theirs (Weil 2010: 14). If animal studies did not exist, there would be no need to confront these moral and ethical dilemmas. Whether desired or not, we will all eventually have to accept that: "Coming from the margins, human-animal studies have the potential to question and deconstruct settled assumptions and to 
gain progressive momentum, similar to other 'counter-hegemonic disciplines"” (The Animal Turn and the Law 2017).

FUNDING: This research received no external funding.

CONFLICT OF INTEREST: The author declares no conflict of interest.

\section{REFERENCES}

Baratay, Eric. 2012. Le point de vue animal. Une autre version de l'histoire. Paris: Seuil. Bakke, Monika. 2011. „Studia nad zwierzętami: od aktywizmu do akademii i z powrotem?” Teksty Drugie 3(129): 193204.

BBC News. 2016. “Belgium Walloons block key EU Ceta trade deal with Canada.” Retrieved January 1, 2017 (https://www.bbc.com/news/world-europe-37749236).

Braidotti, Rosi. 2013. The Posthuman. Cambridge, Malden: Polity.

DeMello, Margo. 2012. Animals and Society: An Introduction to Human-Animals Studies. New York: Columbia University Press.

Domańska Ewa. 2008. „Humanistyka nie-antropocentryczna a studia nad rzeczami.” Kultura współczesna 3: 9-21.

Domańska Ewa. 2008. „Problem rzeczy we współczesnej archeologii.” Pp. 27-60 in Rzeczy i ludzie. Humanistyka wobec materialności, edited by J. Kowalewski, W. Piasek, M. Śliwa. Olsztyn: Wydawnictwo Instytutu Filozofii Uniwersytetu Warmińsko-Mazurskiego.

Empatyczne mizantropki? - wizerunek osób działających w organizacjach pozarządowych na rzecz zwierząt. Raport z badań. 2012. Kraków: Fundacja Czarna Owca Pana Kota. Retrieved October 10, 2019 (https://czarnaowca.org/download/empatyczne mizantropki.pdf).

Gardocka, Teresa, Agnieszka Gruszczyńska, Robert Maślak, Agnieszka Sergiel, eds. 2014. Dobrostan zwierząt $w$ ogrodach zoologicznych a standardy prawne UE. Warszawa: Dom Wydawniczy Elipsa.

Kołacz, Romana and Zbigniew Dobrzański. 2006. Higiena i dobrostan zwierząt gospodarskich. Wrocław: Wydawnictwo Uniwersytetu Przyrodniczego we Wrocławiu.

Mamzer, Hanna. 2008. Poczucie bezpieczeństwa ontologiczne. Uwarunkowania społeczno-kulturowe. Poznań: Wydawnictwo Naukowe UAM.

Mitchell, William J. T. 1994. Picture Theory: Essays on Verbal and Visual Representation. Chicago and London: University of Chicago Press.

Pedersen, Helena. 2014. “Knowledge Production in the 'Animal Turn’: Multiplying the Image of Thought, Empathy, and Justice.” Pp. 13-18 in Exploring the Animal Turn: Human-Animal Relations in Science, Society and Culture, edited by E. A. Cederholm, A. Björck, K. Jennbert, A.-S. Lönngren. Lund: The Pufendorf Institute for Advanced Studies.

Pina e Cuhna Miguel and Armenio Rego. 2018. “Dogs in organizations.” Human Relations 72(4): 778-800. https://doi.org/10.1177/0018726718780210

Pręgowski, Michał P. and Justyna Włodarczyk, eds. 2016. Free Market Dogs: The Hu- 
man-Canine Bond In Post-Communist Poland. West Lafayette, Indiana: Purdue University Press. West Lafayette.

Ritvo, Harriet. 2007. “On the animal turn.” Daedalus 136(4): 118-122: Retrieved November 1, 2016 (https://www.jstor.org/stable/20028156).

Simmons, Laurence and Philip Armstrong, eds. 2007. Knowing Animals. Leiden: Brill.

The Animal Turn and the Law. 2017. Conference: The Animal Turn and the Law: Interdisciplinary Perspectives and New Directions in Animal Law. Retrieved January 1, 2017 (https://animalturn.wordpress.com/about/).

TVN 24. 2016. “Żadnych fajerwerków i petard. Pierwszy taki sylwester w Rzymie.” Retrieved January 1, 2017 (https://tvn24.pl/wiadomosci-ze-swiata,2/zakaz-uzywania-fajerwerkow-i-petard-w-czasie-sylwestra-w-rzymie, 701949.html).

Weil, Kari. 2010. “A Report on the Animal Turn.” Differences: A Journal of Feminist Cultural Studies 21(2): 1-23. DOI: https://doi.org/10.1215/10407391-2010-001.

Wolfe, Cary. 2009. What is Posthumanism? Minnesota: University of Minnesota Press.

Wolfe, Cary. 2011. "Moving forward, kicking back: The animal turn.” Postmedieval: A Journal of Medieval Cultural Studies 2(1): 1-12. DOI: https://doi.org/10.1057/ pmed.2010.46.

\section{BIOGRAPHICAL NOTE}

Hanna Mamzer is professor of sociology at the Adam Mickiewicz University in Poznań, Poland.

OPEN ACCESS: This article is distributed under the terms of the Creative Commons Attribution Non-commercial License (CC BY-NC 4.0) which permits any non-commercial use, and reproduction in any medium, provided the original author(s) and source are credited.

ARTICLE HISTORY: Received 2019-09-04 / Accepted 2019-11-28 
